\title{
Lente in die Teologie: 'n opwindende ligstraal van hoop vir die kerk ${ }^{\bullet}$
}

\author{
J C Müller \\ (Universiteit van Pretoria)
}

\section{ABSTRACT}

\section{The theology of springtime: an exciting ray of hope for the church}

Despite popular opinion, current theology is still in the midst of winter.

In this article the nature of spring - of it as the in-between season is taken as a metaphor for theology: between the lines and prior to the middle. It is a theology beyond fundamentalism whilst preceding relativism. It is a theology in-between the equilibrium of orthodoxy and orthodox practices; in-between confidence and anxiety; prior to right and wrong. It is highly contextual and with people! A spring theology reminds of so many imperative aspects of Practical Theology: people, uncertainty, deconstruction and imagination. This understanding of theology is explained by reference to three relevant issues: (a) gay persons, who have no place in modernistic theology, (b) people with HIV/Aids who have left the church perplexed, ignorant and without large and successful intervention practices and (c) understanding about the creation of the cosmos to those who still accept, adamantly, the Biblical version of creation (of even theorise about it).

\section{INLEIDING}

Lente is ' $n$ tussen-in-seisoen: Tussen winter en somer. Lente is ook 'n duskant-seisoen: Duskant die komende somer. Lente simboliseer natuurlik ook tradisioneel nuwe lewe, skoonheid, jeug en nog baie ander dinge. In hierdie artikel konsentreer ek eerstens op die tussenin en die duskant karakter van lente, terwyl ek die ander nie uit die oog wil verloor nie.

- $\quad$ Hierdie artikel is ' $n$ verwerkte vorm van die oorspronklike referaat wat as een van die hoofreferate by die Lentekonferensie op 28 Oktober 2006, aangebied deur die Fakulteit Teologie, Universiteit van Pretoria, in die Kerkgebou van Universiteitsoord aangebied is. 
Ons sal slegs ' $n$ lente-ervaring in die teologie hê as ons kan leer wat dit beteken om tussen-in en duskant te wees. En dan bedoel ek nie met tussen-in die geykte konsep van tussen God en mens nie. Nie daardie gewilde idee dat ons met óns teologiese konsepte en godsdienstige roeping tussen God en mense kan kom stelling inneem en God verteenwoordig nie. Inteendeel, daardie siening is, wat my betref, juis deel van die winter in die teologie.

Nee, met tussen-in en duskant bedoel ek eerder iets van wat Danie Marais oor Valiant Swart se musiek gesê het ${ }^{1}$. Hy sê Valiant is ' $n$ goeie storieverteller en ' $n$ goeie storieverteller is "per definisie tussen-in en duskant reg of verkeerd". In sy nuutste album, Horisontaal, verklaar Valiant hom "tussen die lyne" en somewhere between:
anderkant die dal
ver oor die vlei
onderdeur die dorings
van die donker vallei
net duskant die middel
van nêrens verby
daar kry jy vir my

\section{Vreemde landskap}

' $n$ Lente-teologie is ' $n$ tussen-in en duskant teologie. Tussen die lyne en duskant die middel. Die teologie waaraan ons te lank gely het, is ' $n$ teologie op die lyntjie en op die middel. Dit is winter-teologie. Ons behoefte vandag in die kerk in Suid-Afrika is aan 'n skoeneuitskop teologie, 'n teologie wat so eerlik kan wees soos Valiant se whisky op ys.

As die teologie nie van die lyntjie en van die middel af gaan ontsnap nie, gaan dit ' $\mathrm{n}$ oom-teologie bly wat vir die jongeling al minder gaan aanspreek. Die Afrikaanse teologie staan voor ' $n$ geweldige uitdaging en kruispad. Die lente wil-wil deurbreek, daar is al ' $n$ paar bloeisels aan die boom, maar daar is ook ' $n$ dreigende yswind wat alles wil verskroei.

Die metafoor van lente help my om twee verwaarloosde, maar uiters opwindende aspekte van teologie weer te beklemtoon: die tussen-in en die duskant karakter daarvan. Die meer gewigtige term

1 Beeld Plus, 23 Augustus 2006, 4. 
wat ek op ander plekke gebruik het en waaroor ek al geskryf het, is postfundamentele teologie ${ }^{2}$. Dit is ' $n$ teologie verby die fundamentele en duskant die relativisitiese; tussen-in die reglynigheid van ortodoksie en ortopraksie; tussen sekerheid en angs; duskant reg en verkeerd; kontekstueel; by mense.

Hierdie verstaan van teologie kan ook verduidelik word aan die hand van die teologiese tipologieë, soos verwoord deur George A. Lindbeck (1984:16-19). Volgens hom is teologieë geneig om aan die hand van een van drie modelle te ontwikkel, naamlik

- Die proposionalistiese model.

- Die ervarings-ekspressiewe model.

- Die kultureel-linguistiese model.

Die proposionalistiese model verteenwoordig die siening dat godsdienstige waarhede by wyse van vaste teologiese proposisies uitgedruk kan word. Hiervolgens is daar ' $n$ baie noue verband en selfs gelykstelling tussen dié waarheid en ons formuleringe van die waarheid. Dit werk met die uitgangspunt dat daar ' $n$ objektiewe waarheid bestaan en dat dit vasgevang en uitgedruk kan word in belydenisuitsprake. Baie van ons teologiese denke is vasgevang in hierdie tipe, aangesien dit gepreokkupeer is met kognitiewe denke en “informational meaningfulness” (Lindbeck 1984:16).

Die ervarings-ekspressiewe model behels volgens Lindbeck ' $n$ benadering wat nie gebaseer is op die idee van ' $n$ objektiewe waarheid en teologiese proposisies nie, maar op ' $n$ algemene kern van menslike godsdienstige ervaringe. Hierdie ervaringe vind binne verskillende kulture verskillende uitdrukkingsvorme. Die werk van Friedrich Schleiermacher, die 19de eeuse teoloog wat beskryf word as die vader van die moderne Protestantse Teologie, is die bekendse eksponent van hierdie teologiese model. Schleiermacher het sy teologie begrond in die algemene menslike ervaring van algehele afhanklikheid. Volgens hierdie model word teologiese formuleringe gesien as pogings om antwoorde te verskaf op menslike ervaringe.

Dan is daar derdens die kultureel-linguistiese model, wat deur Lindbeck verkies word. Hy beskryf hierdie benadering soos volg:

...religions are seen as comprehensive interpretive schemes, usually embodied in myths or narratives and

$2 \quad$ Vergelyk my artikels. 
heavily ritualized, which structure human experience and understanding of self and the world (Lindbeck 1984:32).

Godsdiens is dan soos ' $n$ kultuur of taal wat ' $n$ gemeenskapsfenomeen is. Dit vorm die subjektiewe ervaringe van individue. Dit ontwikkel in ' $n$ woordeskat met simbole wat volgens ' $n$ bepaalde logika of grammatika uitgedruk word. Lindbeck (1984:33) gebruik the term grammar om hierdie teologiese model te verduidelik. Binne ' $n$ bepaalde godsdienstige omgewing of kultuur word godsdienstige taal gebruik en aangeleer. Teologie is vergelykbaar met die grammatika van daardie godsdienstige taal. Teologie is nie soseer ' $n$ opstapeling van ' $n$ aantal belydenisse nie, maar ' $n$ taal wat binne ' $n$ kultuur gebruik word en wat vorm gee aan ons subjektiewe ervaringe. Dit is nie eerstens ' $n$ manifestasie van ons individuele, subjektiewe ervaringe nie, maar ' $n$ konstruering daarvan. Deur die taal wat binne ' $n$ bepaalde kultuur tot ons beskikking is, konstrueer ons ons godsdienstige ervaringe en verfyn dit tot teologiese uitsprake.

Die korrelasie-gedagte of die dialektiek (Tillich), wat deel is van die teologiese benadering wat as ervarings-ekspressief beskryf kan word, is al groot vordering op ' $\mathrm{n}$ proposisionalistiese benadering. Die gevaar is dat dit steeds vasgevang bly in ' $n$ oorvereenvoudigde skema van ' $\mathrm{n}$ heen-en-weer beweeg tussen teologie hier en werklikheid dáár. Die metafoor van teologie as grammatika, binne die kultureel-linguistiese model, help ons verder. Dit help ons om teologie te sien binne 'n netwerk van verhale in plaas van binne die lineêre skema van die dialektiek

So gesien, het teologie ' $n$ skakelbord-taak, of kan ons sommer sê 'n Telkom-taak.

Telkom lê die verbindinge en fasiliteer gesprekke. Telkom is nie ' $n$ eenstop antwoorddiens nie, maar ' $n$ diens wat dit moontlik maak om op soek te gaan na die antwoorde. Volgens hierdie metafoor is teologie nie veronderstel om antwoorde te verskaf nie, maar om ' $n$ konneksie te bewerk tussen ' $n$ verskeidenheid van verhale: Die verhale van die individu, die gesin en familie, die gemeenskap en ook die fundamentele verhaal van die Christelike geloofsgemeenskap. Die taak van die teoloog is dan juis om ' $n$ gesprek te fasiliteer waarbinne die konneksies ontdek, ontgin en in stand gehou kan word. Hierdie verbindinge is natuurlik soms gelaai 
met spanning. Soos die spanning tussen 'n individu en sy gesins/familiestorie; of die spanning tussen die individuele, die gesins- en die kerklike verhaal; of die spanning tussen die algemene moraal en die Christelike etiek; of die spanning tussen politieke en ekonomiese sisteme en die Evangelie. Gerkin (1997:112) sê: "The fit between the particularity of life stories and the Christian story is never exact. They virtually always stand in some degree of tension with each other". Die teologie wat hierdie spanninge probeer ophef deur terug te val op proposisies, werk uiteindelik versmorend. Aan die ander kant is dit lente in die teologie wanneer afgesien kan word van die versoeking om elke spanning op te hef. Die taak van die teologie is eerder om die spanning in al sy kompleksiteit en paradoksaliteit te verwoord en sodoende die moontlikheid te skep dat die lig van die Evangelie daarop kan val.

As ons teologie só probeer verstaan, aan die hand van die metafore van lente (tussen-in en duskant) en die skakelbord, ontwikkel daar ' $n$ teologie wat opnuut die volgende ontdek:

- Mense,

- Voorlopigheid,

- Dekonstruksie,

- Verbeelding.

\section{MENSE}

Dit klink so vanselfsprekend. Maar is dit? Is ons teologie (en religie) met al die mooi God-talk dalk so ver verwyder van gewone mense dat dit dreig om mensvreemd te wees nie? Teologie is veronderstel om ' $n$ mens-wetenskap te wees.

Die "mens" waaroor dit in die teologie gaan is dikwels nie ' $n$ werklike mens nie. Dit is ' $n$ konstruk van ' $n$ mens. ' $n$ Mens wat moet weet hoe groot sy sonde en ellende is en wat dankbaar moet wees vir verlossing. ' $n$ Mens wat by teologiese konstrukte van die antieke tye of by die middeleeue moet inpas. Terwyl die werklike mens wat hier in hierdie vertrek sit en op hierdie kampus rondloop dikwels die werklikheid heel anders beleef. Dit laat hulle vervreemd voel van kerk en godsdiens. En dié wat wel daarin slaag om met die godsdienstige taal van kerk en teologie oor hulleself te praat, word óf self so wêreldvreemd soos die taal wat hulle praat, óf begin leef in twee ongedeelde realiteit: enersyds ' $n$ godsdienstige, dikwels charismatiese realiteit en andersyds ' $n$ alledaagse sekulêre realiteit. 
En skynbaar is die kerke suksesvol daarin om die mense te laat ontvlug in 'n werklikheidsvreemde taal.

Dit sal lente in die teologie wees as die teologie van teks na konteks kan beweeg; as ons tog kan ontdek dat die teks binne die konteks funksioneer en nie die konteks binne die teks nie. Dit sal lente wees as ons ophou om lineêr te probeer dink vanuit die teks na die konteks, maar eerder sirkulêr: konteks-teks-konteks. Dan sal ons ophou om vir mense vanuit tekste te wil voorskryf hoe hulle oor hulleself, oor die wêreld en oor God behoort te dink en eerder begin om by hulle te hoor hoedat hulle hulself ervaar. Om dan van daaruit saam met hulle na te dink oor die konneksies tussen die verskillende verhale waarmee hulle hulle eie realiteite konstrueer.

\section{VOORLOPIGHEID}

Goeie teologie vind jy duskant die waarheid en duskant openbaring. Teologie is soekend na die regte verbindinge. ' $n$ Teoloog moet soos ' $n$ visserman wees wat die vrae (aas) dieper ingooi as waar die opsigtelike antwoorde (vis) lê en loer. Teologie se vrae het te make met die eksistensiële verbindings tussen verhale - verhale oor menswees in ' $n$ bepaalde konteks, verhale oor die ervaring van God se teenwoordigheid te midde van die ervaring van sin en onsin. Die raakvlakke tussen daardie verhale is die ruimte waar teologie binne ' $n$ bepaalde tyd probeer om taal te vind om die bykans onsêbare te verwoord. Daarom is teologiese uitsprake altyd voorlopig.

Teologie is nie anderkant openbaring nie. Teologie is bewus van openbaring, maar ook bewus van die misterie van openbaring. Teologie is nie verwoording van openbaring nie, maar die verwoording van die soeke na, behoefte aan en stamelende voorlopige verwoording van die (ver)skynsels van die openbaring.

Die teologie word te dikwels en te maklik verwoord as vaste proposisies. Ons bedoel dit nie altyd so nie, maar ons teologiese uitsprake kom maklik oor asof ons klaar gedink en in ons denke reeds ' $n$ ekwilibrium (op die middellyn) bereik het. König het onlangs byvoorbeeld ' $n$ boek geskryf waarvan die titel nogal iets van ' $\mathrm{n}$ onsekerheid verwoord (Wat is reg? Weet iemand dalk?). Maar as Rudi Buys ${ }^{3}$, dit resenseer, gee hy erkenning daaraan dat dit gaan oor “ingewikkelde kwessies wat 'n hoë emosionele waarde dra”, maar

3 http://www.litnet.co.za/god/konig_buys.asp, 2006/08/23 
hy kritiseer dit omdat dit hierdie sake... oorvereenvoudig en byna lighartig hanteer. Mens dink: maggies Oom, moet jy nie hieroor nog 'n ent verder gaan werk nie?

Hier sluit ek die gesprekke in oor die huwelik (2), bedelaars (8), Apartheid (10) en die doodstraf (11). Geeneen van dié gesprekke slaag daarin om die kompleksiteit van die kwessie onder bespreking aan te spreek nie.

Die gesprek oor die huwelik gaan oor veel meer as oor watter eggenoot die "CEO van die verhouding" is; dit is verbysterend dat 'n hele gesprek aan die onreg en nalatenskap van Apartheid gewy word, net om teen die einde daarvan die sinvolheid van regstellende aksie te kritiseer. Net so verbysterend is dit om 'n hoofstuk oor bedelaars te wy aan voorstelle oor hoe om dié mense te hanteer, sonder om enigsins die sosiaal-maatskaplike verweefdheid van armoede aan te raak. Om nie eens te praat nie van ' $n$ beredenering van die herinstelling van die doodstraf op grond van wat ooglopend die mees algemeen aanvaarbare mening skyn te wees.

Wat skynbaar by hierdie leser oorgekom het is 'n gebrek aan voorlopigheid, 'n onvermoë om tussen-in die lyne die kompleksiteit van issues verder te ontgin. Dit is nie duskant genoeg nie. Hierdie is maar ' $\mathrm{n}$ voorbeeld, maar dit is tekenend van die neiging van die gevestigde Afrikaanse teologie.

\section{DEKONSTRUEREND}

' $\mathrm{n}$ Teologie wat duskant en tussen-in werk moenie geïnterpreteer word as ' $n$ teologie wat relativisties is en eintlik geen standpunt inneem nie. Om post-fundamenteel te werk, beteken nie om antifundmenteel te werk nie. Dit is ' $n$ benadering wat anders omgaan met die fondamente. Die fondamente word nie langer as proposisies vanuit ' $n$ meerderwaardige en beterweterige posisie verkondig nie. Maar daar word steeds gevra na die fondamente en daar word besin oor die proses waarvolgens fondamente tot stand kom en oorgedra word en hoe dit in 'n bepaalde konteks funksioneer.

Die teologie van Walter Brueggemann is ' $\mathrm{n}$ voorbeeld van so 'n dekonstruerende benadering. Ek haal aan uit sy boek, Finally comes the poet:

The gospel is thus a truth widely held, but a truth greatly reduced. It is a truth that has been flattened, trivialized, and rendered inane. Partly, the gospel is simply an old 
habit among us, neither valued nor questioned. But more than that, our technical way of thinking reduces mystery to problem, transforms assurance into certitude, revises quality into quantity, and so takes the categories of biblical faith and represents them in manageable shapes. (Brueggemann 1989:1-3)

To address the issue of a truth greatly reduced requires us to be poets that speak against a prose world...By prose I refer to a world that is organized in settled formulae, so that even pastoral prayers and love letters sound like memos. By poetry, I do not mean rhyme, rhythm, or meter, but language that moves like Bob Gibson's fast ball, that jumps at the right moment, that breaks open old worlds with surprise, abrasion, and pace.

Such preaching is not moral instruction or problem solving or doctrinal clarification. It is not good advice, nor is it romantic caressing, nor is it a soothing good humor.

It is, rather, the ready, steady, surprising proposal that the real world in which God invites us to live is not the one made available by the rulers of this age (Brueggemann 1989:6-9)

Dekonstruksie word dikwels verwar met 'n afbrekende aksie. Dan word dit voorgestel as ' $n$ negatiewe, vernietigende benadering. Dekonstruksie, volgens die Franse filosowe, Derrida en Foucault, is egter nie om bloot af te breek nie, maar ' $n$ blootlegging van mag binne sisteme. Daarom is dit nie 'n waarde-vrye en relatiwistiese benadering nie, maar ' $\mathrm{n}$ proses wat gedryf word deur die waardes van respek en gelyke verhoudinge. Dit behels ' $n$ onvrede met magsmis-bruik en ' $n$ strewe na die bemagtiging van gemarginaliseerdes.

'n Teologie van dekonstruksie is dus 'n teologie wat sosiaaleties betrokke raak. Dit is ' $n$ teologie wat tussen die lyne lees, wat nie die boodskappe soos opgedis deur die invloedrykes, bloot as die waarheid aanvaar nie. Dit is ' $n$ teologie wat nie vasgevang is in die diskoerse van die meerderheid en daarom van populariteit nie.

\section{VERBEELDING}

Richard Kearney (2001:1-2) begin sy boek, The God Who May Be, met die volgende paragraaf:

God neither is nor is not but may be. That is my thesis in this volume. What I mean by this is that God, who is 
traditionally thought of as act or actuality, might better be rethought as possibility.

Instead of seeing possibility as some want or lack to be eradicated from the divine so that it be recognized as the perfectly fulfilled act that it supposedly is, I proffer the alternative view that is divinity's very potentiality-to-be that is the most divine thing about it.

Soos ek dit verstaan, is dit presies die boodskap van die opstanding. God is die Immer Moontlike. God wat net nie in taal van is of is nie vasgevang kan word nie. Die God oor wie en vir wie en van wie ons eintlik geen woorde het nie. Daarom is die taal van die teologie wat by die lente van die opstanding pas, die taal van verbeelding; die taal wat dit waag om die moontlike van die onmoontlike te probeer sê. Dit is die taal waarna die Nederlandse priester-digter, Huub Oosterhuis verwys met die begrip "tweede taal". Dit is die "taal wat eigenlijk niet te zeggen is. Die je spreekt om niet helemaal te hoeven zwijgen.” (sien Müller 2006:42)

Dit is die taal wat die teologie, na die winter van die modernisme, weer moet herontdek en leer praat. Ons teologie ly nog erg onder die Verligting. Die taal van die modernisme was en is die taal van die Verligting. Die hele vorige eeu se teologisering is daardeur beïnvloed. Dit is taal wat streef na letterlikheid en korrektheid. En hoe meer lettelik en korrek, hoe leër het dit geword. Laat ons dankbaar wees vir die postmodernisme wat weer kreatiwiteit en verbeelding na vore bring. Nou kan ons weer vry en nuut na die Bybelse verhale teruggaan en dit ten minste probeer lees sonder die tonnelvisie van die dogmas. Nou kan ons die Bybel in al sy paradoksaliteit, relatiwiteit en onsekerheid herontdek.

\section{MOONTLIKE BLOEISELS}

In hierdie laaste deel van die voordrag gaan ek die tussen-in- en die duskant-karakter van die teologie probeer verduidelik aan die hand van drie konkrete kontekste:

- Homoseksualiteit,

- MIV/VIGS en gesondheid,

- Skepping en evolusie.

\subsection{Homoseksualiteit}

Homoseksualiteit word ' $\mathrm{n}$ onoorkomelike probleem binne modernistiese teologiese denkraamwerke. Daarvolgens word die Bybelse 
uitsprake met ' $\mathrm{n}$ hermeneutiek van anderkant en nie duskant gelees nie. Iemand het die opmerking gemaak dat die debat oor homoseksualiteit in die Nuwe Testament afgesluit is. Al wat dus oorbly is om die reeds verworwe standpunte so liefdevol moontlik toe te pas. Die kompleksiteite van dit wat tussen die lyne gevind word, moet liefs vermy word omdat dit ervaar word as ' $\mathrm{n}$ poging om die hardheid en duidelikheid van die Bybelse uitsprake te ondergrawe.

' $n$ Pastorale model wat op hierdie benadering geskoei is, sou dus hoogstens die homoseksuele persoon kon aanvaar, maar daarmee saam dan altyd ' $n$ aandrang op, of verkondiging van ' $n$ selibate lewenstyl. Dit word 'n ongenaakbare "pastoraat"/teologie wat met voorafingenome proposisies, sonder aansiens des persons, die "waarheid" verkondig. Ongeag die konteks en agtergrond, word die homoseksuele persoon eenvoudig gekonfronteer met slegs een opsie waarvolgens aan die Bybel getrou gebly kan word. Binne hierdie teologiese raamwerk hoor mens dan dikwels die cliché: "Ek aanvaar jou met die liefde van Jesus, maar die Bybel laat my geen ander keuse as om van jou te verwag om jou homoseksuele aard op geen manier uit te leef nie.”

Dit is met hierdie proposisionalistiese teologie wat duisende gay-lidmate steeds van die kerk vervreem word. Hulle word deur predikante aangemoedig om aan die onmenslikste vorme van terapie, soos aversie-terapie, onderwerp te word. In 'n pastoraat waar teologiese formulerings gelykgestel word aan die waarheid, kom alles eventueel daarop neer dat die sondaar hom/haar moet bekeer om in lyn te kom met die bepaalde proposisies. Dit maak nie saak of hulle kan of nie. Hulle moet!

Die meer genaakbare pastorale benaderings wat in die afgelope dekades beslag gekry het, het grootliks uit die ervaringsekspressiewe model van teologiebeoefening gespruit. Dit het daartoe gelei dat aan die gay-gespreksgenoot ' $n$ eerlike geleentheid gegee is tot selfekspressie. Hulle is ten minste nie by voorbaat as sondig afgeskiet nie. Tog het die pastorale gesprek ook binne hierdie benadering dikwels doodgeloop omdat rigiede en on-kontekstuele skrifinterpretasie die korrelasie by voorbaat onvrugbaar gemaak het. Dan word die pastorale proses met die homoseksuele persoon eintlik nog meer ongenadig, as binne die proposionele model. Want die gevaar is nou dat juis met die meer genaakbare proses, valse hoop 
gewek word en dat die pastorale diskussies uitgerek word om tog maar uiteindelik by dieselfde ongenaakbare cliché te eindig. "Want die Skrif laat ons geen ander keuse nie”!

Met dieselfde soort teologie kan natuurlik 'n soortgelyke, maar teenoorgestelde standpunt gevorm word, wat ewe onwrikbaar vanuit ' $n$ bepaalde interpretasie gehandhaaf word. Dan word homoseksualiteit met eweveel passie vanuit teologiese proposisies verdedig. En dan gaan dit eweneens nie oor mense van vlees en bloed nie, maar oor ' $n$ kategorie van mense wat ten alle koste verdedig moet word.

Met ' $n$ teologie wat bewus is van sy eie voorlopigheid, word daar eerder ondersoek ingestel na die magsdiskoerse wat hier aan die werk is. Daarom kom vrae oor homofobie in kerk en samelewing ook in die gesigsveld. Die vraag is ook wie is die persone wat so magtig en afwysend, of simpatiek en insluitend die Bybel vir homoseksuele persone uitlê?

Met dekonstruksie en verbeelding in gedagte, word die konnek-sies tussen die netwerk van verhale weer bedink en hervertel met die oog daarop om nuwe moontlike konneksies te ontgin. Die verband (verbond) met die grondverhaal van die Christelike geloof word binne die konteks van homoseksualiteit van nuuts af bevraagteken, bevestig en desnoods gewysig ten einde 'n unieke en betekenisvolle uitdruk-king van Christelikheid te vind. Dan gaan daar nog ' $\mathrm{n}$ lentebloeisel vir die teologie oop.

\subsection{MIV/Vigs en gesondheid}

Die tweede konteks is MIV en VIGS. Die tradisionele teologiese denkraamwerke laat weinig ruimte om MIV/VIGS en gesondheid op enige ander basis as die moreel-etiese te benader. Daar word vasgesteek by die feit dat MIV en VIGS ' $n$ seksueel oordraag-bare siekte is en daarom met ' $n$ korrekte lewensstyl vermy kan word. Ek was ' $n$ paar jaar gelede by ' $n$ konferensie van die Suid-Afrikaanse Raad van Kerke, waar ' $n$ groot groep predikante van verskillende kerke in die debat oor die kerke se rol in die bekamping van VIGS, uiteindelik nie verder gekom het as ' $\mathrm{n}$ gestry oor condomise of nie.

Dit is slegs ' $n$ teologie wat tussen-in en duskant opereer wat mens toelaat om na die groter prentjie te kyk. Dan besef ons dat ons eers betekenisvol oor hierdie pandemie kan saampraat indien ons iets begin begryp van die sosiaal-ekonomiese magsdiskoerse wat sommige mense net soveel minder keusemoontlikhede bied as ander. Dit 
is waarskynlik met só ' $\mathrm{n}$ teologie wat Christina Landman ' $\mathrm{n}$ tyd gelede in Beeld ${ }^{4}$ die gevaarlike ding gedoen het om die minister van gesondheid, Dr Manto Tshabalala-Msimang te verdedig. In die artikel vra sy begrip vir ' $\mathrm{n}$ meer holistiese beskouing oor siekte en gesondheid. Sy beoefen ' $n$ teologie wat nie klaar met westerse kategorieë gearriveer het en al die antwoorde ken nie. Sy huiwer nog aan die duskant van antwoorde en vra vir die insig dat "beterword ' $n$ proses is, ' $n$ omvattende proses wat goeie verhoudings, goeie kos en verskillende goeie medisyne insluit, Westers en inheems”. Ek self is nie geneë om die minister van gesondheid te verdedig nie. Ek dink sy tree nie in die eerste plek op in belang van die mense wat ly aan en onder MIV en VIGS nie. Ek stem egter saam met Landman dat ons ' $n$ behoefte het aan ' $n$ groter en meer inklusiewe perspektief en dit is slegs 'n postfundamentele teologie wat werklik interdissiplinêr werk wat dit vir ' $n$ mens toelaat.

\subsection{Skepping en evolusie}

Met die beplande besoek van die kreasionis, Kent Hovind, aan SuidAfrika in Augustus vanjaar (die besoek het toe skipbreuk gely omdat die VSA, as gevolg van belastingontduiking, nie reisdokumente aan Hovind wou uitreik nie) het die hele debat oor skepping en evolusie weer na die voorgrond gebring.

Dit blyk dat daar heelwat Christene en selfs teoloë is ${ }^{5}$ wat die teorie van evolusie verwerp en wat vashou aan ' $n$ letterlike verstaan van die Genesis 1-3 verhale. So ' $n$ standpunt kan natuurlik slegs gehandhaaf word indien die interdissiplinêre gesprek nie werklik ernstig opgeneem word nie, aangesien die oorwig van getuienis van natuurwetenskaplikes duidelik die teorie van evolusie aanvaar. Slegs wanneer met 'n teologie van "anderkant” gewerk word, kan daar so maklik met meerderwaardigheid besluit word oor die waarheid of leuen van wetenskaplikes se bevindinge. Binne ' $n$ postfundamentele teologiese denkraamwerk waar voorlopigheid en daarom ook interdis-siplinariteit hoog geag word, kan daar nie so maklik afwysende uitsprake gemaak word nie. Met so 'n teologiese

4 'n Pil alleen kan jou nie gesond maak, Beeld, 21 Augustus 2006

5 Sien byvoorbeeld die brief van Ds Theo Dansfuss in Kerkbode van 11 Augustus waarin doodgewoon praat van die "dwaalleer van evolusie" en waarin hy Kent Hovind se standpunte oor die letterlike verstaan van Genesis 13 verdedig. 
uitgangspunt moet die teoloog met nederigheid en terughoudendheid luister na die bevindinge van ander en in ' $n$ ernstige gesprek met hulle tree om te soek na transversale rasionaliteit ${ }^{6}$. Dit is juis hierdie benadering wat Wentzel van Huysteen in ' $n$ fassinerende en respekvolle gesprek laat tree met paleo-antroploë en argeoloë. Dit bring hom daartoe om in sy nuutste boek, Alone in the World, die werk van hierdie kundiges te erken en saam te soek na transversale rasionaliteit oor die oorspronge van ons spesie. Van Huyssteen (2006:165) sê:

Whether theologians or scientists, however, we will certainly never properly understand how we became what we are without first identifying our links to other earlier hominids in a normal biological context, and asking about our origins of species. On a scientific level, of course, this task falls to paleo-anthropologists and archeologists, scientists involved deeply in uncovering evidence of the human past.

Daarteenoor verstom ' $n$ mens jou oor ' $n$ uitspraak van Gerrit Claassen in Kerkbode van 28 Julie 2006:

Hoewel hierdie feite interessant is, bly dit steeds ondergeskik aan God se Woord wat leer dat die hemel en aarde in ses letterlike, opeenvolgende dae van 24 elk, sowat 6000 jaar gelede, geskep is (p 16).

Daar kan natuurlik alleen tot so ' $\mathrm{n}$ uitspraak gekom word op grond van ' $n$ proposisionalistiese en fundamentalistiese teologie wat jou toelaat om vanuit ' $n$ bepaalde Bybelse interpretasie die bevindinge in ander vakgebiede af te skiet.

Wanneer die lente in die teologie deurbreek en daar iets meer van ' $n$ tussen-in en duskant funksioneer, raak teoloë nederige, betroubare, gerespekteerde en respekterende gespreksgenote wat saam soek na die waarheid.

\section{UITEINDELIK: DIE OORHAND VAN DIE LEWE}

$\mathrm{Al}$ het ek in hierdie voordrag die klem op die tussen-in en duskant aspekte van lente gelê, is dit tog onmoontlik om die metafoor van die lente te laat verbygaan sonder om die mees voor-die-handliggende

6 Sien die werke van Wentzel Van Huyssteen (2006:9, 18-23), byvoorbeeld sy jongste boek, Alone in the World? 
aspek daarvan uit te lig: Lente staan vir lewe - lewe wat weerbarstig en onweerstaanbaar deurbreek. Daarom moet teologie wat deur die metafoor van lente gedra word, 'n teologie van die lewe wees. Dit wil sê teologie van die hoop, lewe, optimisme, blydskap en uitsig.

In die museum in Hiroshima wat die effek van die A-bom op die stad in Augustus 1945 uitbeeld, is daar tussen al die neerdrukkende fotos van verbrande mense en ' $n$ verskroeide stad, ook ' $n$ foto van ' $n$ kanna-blom wat tussen die rommel opgekom en begin blom het. In die herfs was dit vir die oorlewendes 'n teken van lente. Na die bom het die wetenskaplikes voorspel dat daar vir 75 jaar niks in daardie omgewing sal groei nie. Die kanna het hulle na ' $n$ paar weke verkeerd bewys en dit het die simbool van hoop geword vir 'n platgeveegde stad.

Hierdie is die finale en belangrikste kriterium vir die teologie van die lente. Dit moet die boodskap van hoop en verwagting dra te midde van al die tekens van die dood! Die vraag is of dit ' $n$ teologie van lewe en blydskap is, of staan dit in die teken van terneergedruktheid? Vir die gewone mens sal teologie waarskynlik eerder geïdentifiseer word met ' $n$ blok aan die been, as met ' $n$ vrolike en dartelende vlieër wat 'n mens 'n slag kan laat opkyk.

Die klagtes oor leerdwaling wat nou vir meer as twee jaar soos ' $n$ droë woestynwind oor die teologiese landskap gewaai het, het die beeld van kerk en teologie in Suid-Afrika verskroei. Die indruk wat gewek is, is dat teologie inderdaad iets gevaarliks is om jou mee besig te hou. Kollegas van ander vakgebiede het by herhaling aan ons gesê hoe dankbaar hulle is dat hulle nie in die teologie doseer nie, want hulle word nie aan bande gelê deur konvensies nie. Hulle kan hulle wetenskap eerlik en onbevange beoefen. In die teologie is dit skynbaar nie moontlik nie. As jy in dié vakgebied werk, moet jy die heeltyd oor jou skouer loer om seker te mak dat jy nie onder skoot gaan kom nie. En dan gaan dit nie oor die goeie en gesonde kontrole van 'n wetenskaplike gemeenskap nie, maar die neerdrukkende kontrole van leerpuriste wat hulleself aanstel as die polisie van die suiwere leer, op grond van ' $n$ proposisionalistiese teologie. So ' $n$ toestand is soos die dood in die pot vir die beoefening van die teologie en terwyl dit voortduur is daar nie sprake van lente in die teologie nie.

Tog is dit juis die gebeure van die afgelope jaar wat die teologie in ons konteks weer voor 'n kairos-oomblik te staan gebring 
het. Ek is oortuig daarvan dat ons opnuut geroep word om te kies teen ' $n$ kontrolerende, proposisionalistiese teologie en vir ' $n$ teologie wat die uitdaging aanvaar om

- 'n teologie vir mense te wees;

- sy eie voorlopigheid te verwoord;

- om moedig te dekonstrueer aan die magsdiskoerse in die samelewing;

- om verbeeldingryk en waagmoedig nuwe taal te gebruik om ons ervaring van menswees voor die aangesig van God te verwoord.

Mag hierdie lenteskool en dalk selfs hierdie lesing daartoe bydrae om soos die lente weerbarstig en onkeerbaar weerstand te bied teen die wintersdood in kerk en teologie!

\section{Literatuurverwysings}

Brueggemann, W 1989. Finally comes the poet: daring speech for proclamation. Minneapolis: Fortress Press.

Buys, R 2006. König raak my aan, en sit my pot mis: 'n resensie. http://www.litnet.co.za/god/konig_buys.asp, 2006/08/23

Claasen, G Kerkbode. 28 Julie 2006.

Gerkin, C V 1997. An introduction to pastoral care. Nashville: Abingdon.

Kearney, R 2001. The God Who May Be: Hermeneutics of Religion. Bloomington, IN: Indiana University Press.

Landman, C 2006. 'n Pil alleen kan jou nie gesond maak. Beeld. 21 Augustus 2006.

Lindbeck, G A 1984. The Nature of Doctrine: Religion and Theology in a Postliberal Age. Philadelphia: Westminster Press.

Marais, D 2006. Beeld Plus. 23 Augustus 2006.

Müller, J 2006. Opstanding. Wellington: Lux Verbi-BM.

Müller, J C 2005. Postfoundationalism and HIV-positive practical theology. Practical Theology in South Africa, 2005,

Müller, J C 2005. A Postfoundationalist, HIV-positive practical theology. Practical Theology in South Africa 20(2) 2005, 72-88.

Müller, J C 2004. HIV/AIDS, Practical Theology, and Postfoudationalism. The emergence of a new story. Hervormde Teologiese Studies 60(1 \& 2), Maart \& Junie 2004, 293-306.

Van Huyssteen, W 2006. Alone in the world? Grand Rapids, Michigan: William B. Eerdmans. 